\title{
CSI(T1) WITH PHOTODIODES FOR IDENTIFYING SUBSURFACE RADIONUCLIDE CONTAMINATION
}

D. C. Stromswold

J. E. Meisner(a)

W. F. Nicaise ${ }^{(a)}$

October 1994

Presented at the

Institute of Electrical and Electronics Engineers Nuclear

Science Symposium

October 30 - November 5, 1994

Norfolk, Virginia

Prepared for

the U.S. Department of Energy

under Contract DE-AC06-76RLO 1830

Pacific Northwest Laboratory

Richland, Washington 99352
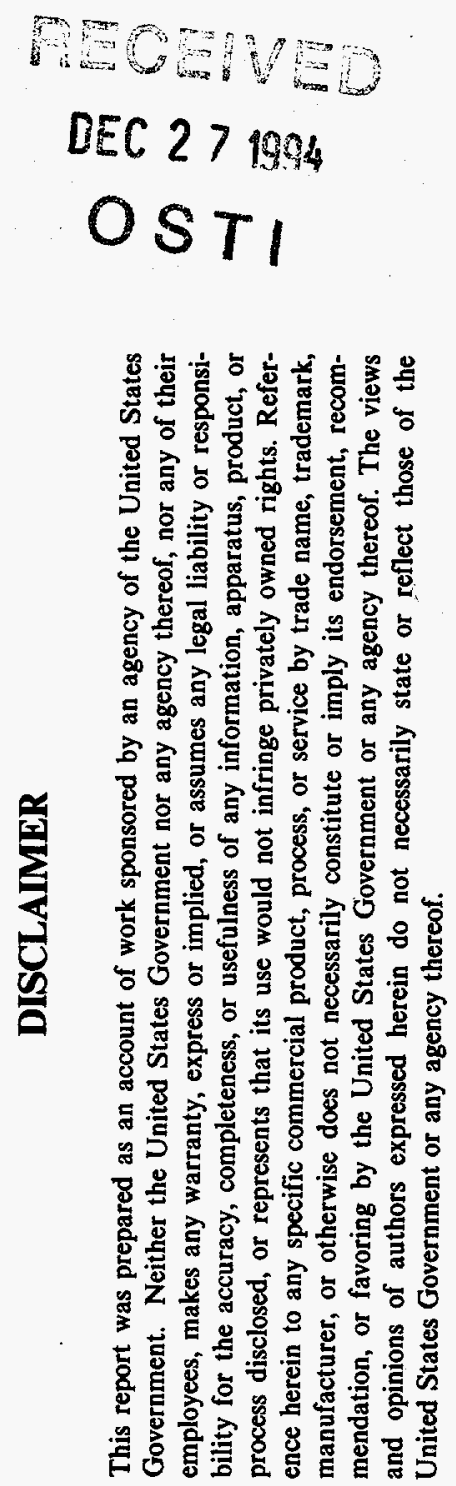

(a) Westinghouse Hanford Company, Richland, Washington 


\section{DISCLAIMER}

Portions of this document may be illegible in electronic image products. Images are produced from the best available original document. 


\title{
CsI(Tl) with Photodiodes for Identifying Subsurface Radionuclide Contamination
}

\author{
J. E. Meisner and W. F. Nicaise \\ Westinghouse Hanford Company \\ P.O. Box 1970 \\ Richland, WA 99352 \\ D. C. Stromswold \\ Pacific Northwest Laboratory \\ P.O. Box 999 \\ Richland, WA 99352
}

\begin{abstract}
A cylindrical $(15 \times 61 \mathrm{~mm})$ CsI(Tl) scintillation detector with two side-mounted photodiodes has been developed to collect spectral gamma-ray data in subsurface contaminated. formations at the U.S. Department of Energy's Hanford Site. It operates inside small-diameter, thick-wall steel pipes pushed into the ground to depths up to $20 \mathrm{~m}$ by a cone penetrometer. The detector provides a rugged, efficient, magnetic-field-insensitive means for identifying gamma-rayemitting contaminants (mainly ${ }^{137} \mathrm{Cs}$ and $60 \mathrm{Co}$ ). Mounting two $3 \times 30-\mathrm{mm}$ photodiodes end-to-end on a flat area along the detector's side provides efficient light collection over the length of the detector.
\end{abstract}

\section{INTRODUCTION}

At the U.S. Department of Energy's Hanford Site near Richland, Washington, underground radioactive contamination exists as the result of leaks, spills, and intentional disposal of waste products from plutonium-production operations. Characterizing these contaminants in preparation for environmental remediation is a major effort now in progress.

Drilling boreholes through potentially contaminated zones can be a very expensive process that has the possibility of spreading contamination and exposing workers to radiation. Cone penetrometers offer an alternative way to make holes in subsurface formations without actual drilling. In this process, thick-walled steel pipes with solid cone-shaped tips are pushed into the ground to make access holes. These pipes typically have a small diameter (O.D. $<5 \mathrm{~cm}$ ) to facilitate ground penetration. The resistance of the ground to insertion of the pipes provides a measure of soil strength [1]. Once the pipes are in the ground, sensors can be lowered into them and samples of subsurface liquids or soils can be retrieved [2-3]. Radiation detectors placed in the pipes can measure the density and moisture of the soil using scattered radiation from a gamma-ray or neutron source in the pipes [4]. In the present study, spectrometry is used to determine gamma-rayemitting contaminants present in the subsurface near cone penetrometer pipes.
An experimental $\mathrm{CsI}(\mathrm{Tl})$ detector with side-mounted photodiodes has been constructed to measure gamma radiation through cone penetrometer pipes. Although photodiodes have been used with CsI(TI) detectors for other applications [5-10], this is believed to be the first use of scintillator/photodiodes for subsurface (well logging) applications. The CsI(TI) detector is a cylinder with a flat surface for mounting two photodiodes along its length. This differs from conventional detectors with photodiodes that are mounted on the end of a rectangular or square scintillator. The basically cylindrical geometry of the detector helps to maximize the detector volume that can be used inside the access pipes. Two rectangular $(3 \times 30-\mathrm{mm})$ diodes placed end-to-end axially on the side of the CsI(T) cylinder provide light collection along the length of the detector. The CsI(Tl) crystal offers better sensitivity to high-energy gamma rays than does $\mathrm{NaI}(\mathrm{Tl})$, and its light-output spectrum is compatible with the photodiodes.

Photodjodes offer some distinct advantages over photomultiplier tubes in cone penetrometer applications. They enable the detector assembly to be short $(<20 \mathrm{~cm}$, including electronics), reducing the chances of its becoming stuck inside the penetrometer pipe, which can bend during insertion into the ground. The insensitivity of photodiodes to magnetic fields is advantageous for spectral measurements in pipes that can become magnetized. Rugged construction and low bias voltage $(70 \mathrm{~V})$ make the detector assembly suitable for field use. In addition, small drifts in the bias voltage do not affect output pulses. Photodiodes work well in the conepenetrometer application where contaminant identification, not quantification, is needed. In other applications, where larger diameters are possible, photomultipliers can be a better choice (unless high magnetic fields are present) since no gain matching of multiple diodes is needed.

\section{DETECTOR WITH PHOTODIODES}

\section{Energy Resolution}

The $15 \times 61 \mathrm{~mm}$ CsI(TI) detector has two $3 \times 30 \mathrm{~mm}$ photodiodes mounted end-to-end on its side. The individual outputs for the two photodiodes are matched so that summing 



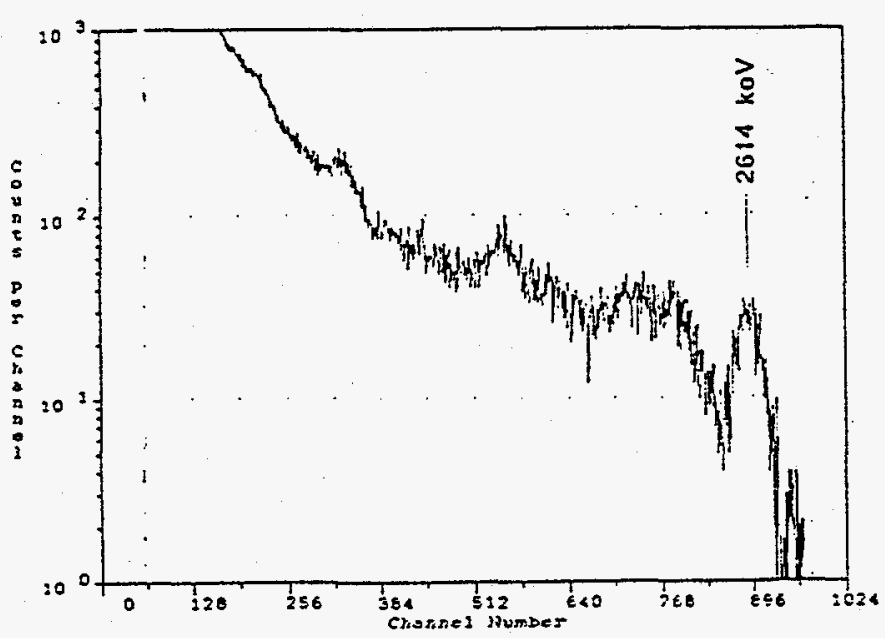

Fig. 4. Spectrum obtained in Th calibration model. Counting time $=1000 \mathrm{~s}$.

Data from the calibration models do not provide a direct calibration for typical radioactive contaminants, such as $137 \mathrm{Cs}$ and $60 \mathrm{Co}$, in the subsurface at Hanford. Based on the energydependent efficiency of the detector and the known gamma-ray production of these contaminants, however, it is possible to estimate their concentrations using the following equations [12]:

$$
\text { Conc }(B q / g)=I(E) A_{x} / N_{x}
$$

or

$$
\text { Conc }(p C i / g)=27\left[I(E) A_{x} / N_{x}\right]
$$

where $I(E)$ is the energy-dependent inverse efficiency (gamma/s/c/s) of the detector obtained from calibration, $A_{x}$ is the count rate in the photopeak, and $N_{x}$ is the number of gamma rays emitted per decay of element "x.".

\section{FIELD TEST RESULTS}

Collecting data with the detector in a cone penetrometer hole at Hanford that penetrated a zone containing $137 \mathrm{Cs}$ yielded the spectrum shown in Fig. 5. A waste disposal pond, identified as $U-10$, was once present at this location. The pond received approximately $2 \times 10^{11} \mathrm{l}$ of low-level liquid contaminants including $90 \mathrm{Sr},{ }^{137} \mathrm{Cs}$, plutonium, and uranium [13]. The contamination settled to the bottom of the pond, which now contains no water, and indeed, has several feet of added overburden above the original surface to reduce radiation levels at the present ground level. The $662-\mathrm{keV}$ gamma-ray peak is clearly visible in the figure. The concentration of ${ }^{137} \mathrm{Cs}$ is estimated to be approximately $5 \mathrm{nCi} / \mathrm{g}(200 \mathrm{Bg} / \mathrm{g})$, based on these measurements and Eqs. 1 and 2 . For this estimate the detector efficiency was assumed to be the same at the $609-\mathrm{keV}$ calibration peak in the $\mathrm{U}$ spectrum (Fig. 3) and at $662 \mathrm{keV}$ for ${ }^{137} \mathrm{Cs}$. The extensive low-energy continuum in the Fig. 5 is believed to be due to bremsstrahlung from the beta particles emitted from ${ }^{90} \mathrm{Sr}$ and 90Y. Figure 6 shows the vertical profiles obtained by moving the detector through the cone penetrometer pipe. The figure shows both the count rates from the ${ }^{137} \mathrm{Cs}$ photopeak and the gross count rates obtained by integrating all counts in the spectra.

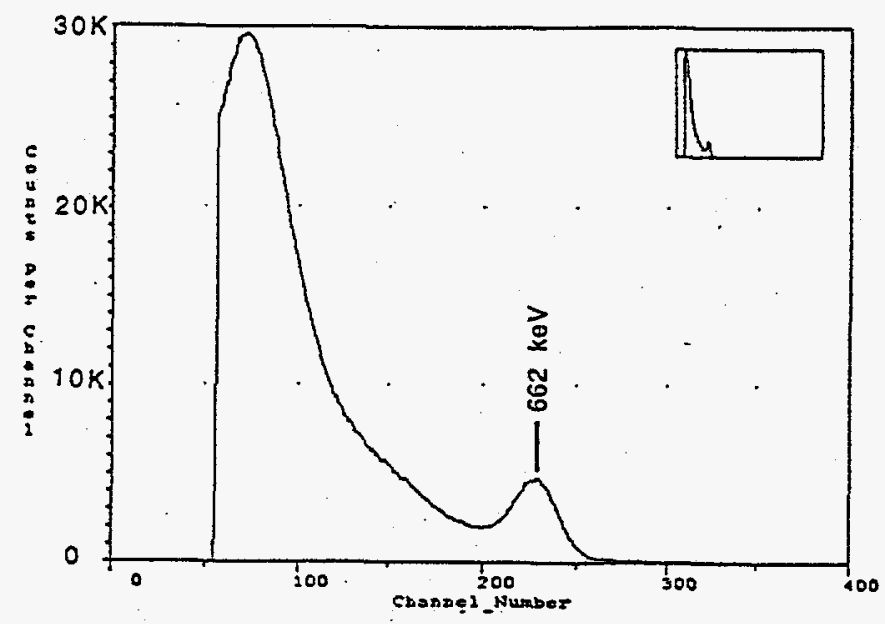

Fig. 5. Spectrum from cone penetrometer hole at Hanford contaminated site showing ${ }^{137} \mathrm{Cs}$ gamma-ray peak and ${ }^{90} \mathrm{Sr} / 90 \mathrm{Y}$ bremstrahlung (low-energy continuum). Counting time $=200 \mathrm{~s}$.

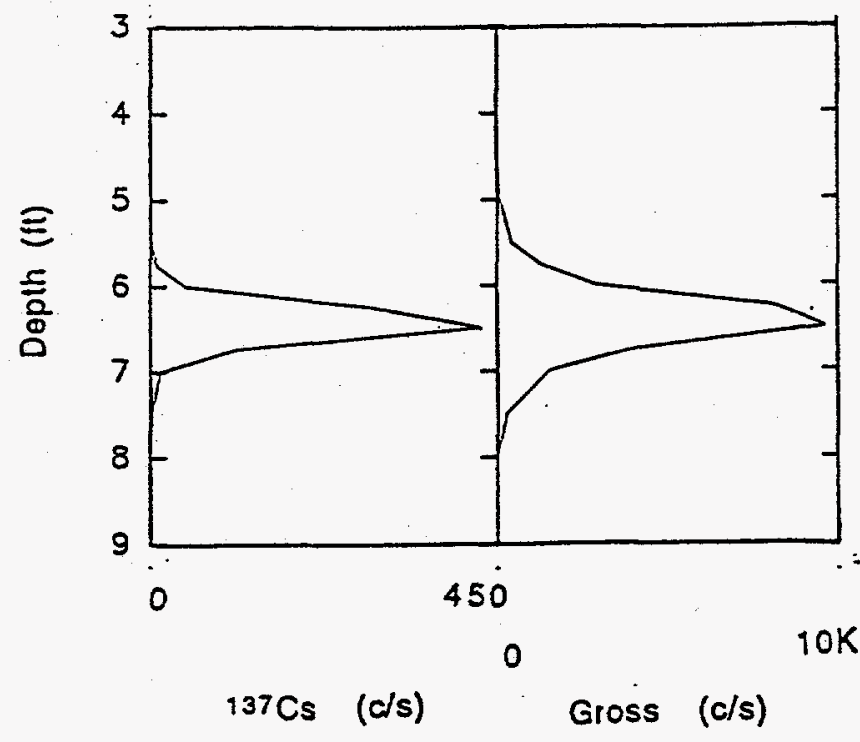

Fig. 6. Vertical profile of count rates obtained through contaminant interface. Count rate in ${ }^{137} \mathrm{Cs}$ photopeak plotted on left; gross count rate on right. 


\section{CONCLUSION}

For environmental assessment and remediation of radionuclide contamination, spectral gamma-ray measurements through penetrometer pipe can produce rapid, relatively low cost assessments of subsurface contamination. Cone penetrometers have the advantage over conventional drilling of not bringing contaminated waste to the surface in either drill cuttings or circulating fluid. In addition, new penetrometer techniques (e.g., vibratory insertion) are making possible the use of penetrometers in areas where ordinary techniques had been unable to penetrate some formations.

The ability to identify specific radionuclides by spectral gamma-ray measurements in the small-diameter, thick-wall cone penetrometers provides distinct advantages over more conventional gross gamma-ray measurements. In areas where multiple gamma-ray-emitting contaminants are present, the spectral measurements can provide information on the distributions of these materials.

\section{ACKNOWLEDGEMENTS}

The U.S. Department of Energy (DOE) funded this work with Westinghouse Hanford Company (WHC) under contract DE-AC06-87RL10930. Battelle Memorial Institute operates Pacific Northwest Laboratory (PNL) for DOE under contract DE-AC06-76RLO 1830. The authors appreciate the approval of DOE, WHC, and PNL to publish this material. The CsI detector with side-mounted photodiodes was constructed by $\mathrm{eV}$ Products, Saxonburg, Pennsylvania.

\section{REFERENCES}

[1] J.A. Harison, "Correlation between California bearing ratio and dynamic cone penetrometer strength measurement of soils," Proc. Inst. Civil Eng. (London), vol. 83, pt. 2, pp. 833-844, 1987.

[2] M.G. Serrato, R.S. VanPelt, S.R. McMullin, J. Rossabi, "Application of cone penetrometer testing technology in waste site investigations at SRS," Trans. Amer. Nucl. Soc., vol. 68, pt. A, pp. 54-55, 1993.

[3] S..H. Lieberman, S.E. Apitz, L.M. Borbridge, and G.A. Theriault, "Subsurface screening of petroleum hydrocarbons in soils via laser-induced fluorometry over optical fibers with a cone penetrometer system," Proc. of SPIE - The Int. Soc. for Optical Eng. (Bellingham, Washington), vol. 1716, pp. 392-402, 1993.

[4] T. Shibata, M. Mimura, A.K. Shrivastava, M. Nobuyama, "Moisture measurement by neutron moisture cone penetrometer: design and application," Soils and Foundations, vol. 32, no. 4, pp. 58-67, 1992.
[5] A.J. Bird, T. Carter, A.J. Dean, D. Ramsden, "The optimization of small CsI(Tl) gamma-ray detectors," IEEE Trans. Nucl. Sci., vol. 40, no. 4, pp. 395-397, 1993.

[6] M. Asghar and D.C. Imrie, "Silicon photodiodes as photomultiplier replacements in industrial scintillation counters," J. Physics, E (London), Sci. Instr., vol. 22, no. 12, pp. 1012-1015, 1989.

[7] C. Labanti, E. Caroli, E. Rossi, A. Spizzichino, "Methods for optimizing the performances of positionsensitive CsI(Tl) scintillation bars with photodiode readout," Nucl. Inst. Meth. Phys. Research, vol. A310, no. 1-2, pp. 327-331, 1991.

[8] C. Carrier and R. Leconte, "Recent results in scintillation detection with silicon avalanche photodiodes," IEEE Trans. Nucl. Sci., vol. 37, no. 2, pp. 209-214, 1990.

[9] R. Sakai, "Recent measurements on scintillatorphotodetector systems," IEEE Trans. Nucl. Sci., NS-34, no. 1, pp. 418-422, 1987.

[10] H. Grassmann, H.G. Moser, H. Dietl, G. Eigen, V. Fonseca, E. Lorenz, and G. Mageras, "Improvements in photodiode readout for small CsI(Tl) crystals," Nucl. Inst. Meth. Phys. Research, A234, pp. 122-124, 1985.

[11] D.C. Stromswold, "Calibration facilities at Hanford for gamma-ray and fission-neutron well logging," PNL-9958, Pacific Northwest Laboratory, Richland, Washington, July, 1994.

[12] C.J. Koizumi, J.R. Brodeur, R.K. Price, J.E. Meisner, and D.C. Stromswold, "High-resolution gamma-ray spectrometry logging for contamination assessment," Nucl. Geophys., vol. 8, pp. 149-164, 1994.

[13] G.G. Kelty, "Description of work for 216-U-Pond cone penetrometer demonstration," WHC-SD-EN-AP-142, Westinghouse Hanford Company, Richland, Washington, 1993. 